\title{
Discussion on Strategies of Internal Leadership in Chinese Non-Profit Organizations (NPOs)
}

\author{
Wei Li \\ School of Economics \& Management, Changchun University of Science \& Technology \\ Changchun 130022, China \\ \& Post doctorate, Business School, Jilin University, Changchun, China \\ Tel: 86-431-8583-9869Ｅ-mail: leewei5545@126.com
}

Received: August 12, 2011

Accepted: August 30, $2011 \quad$ Published: December 1, 2011

doi:10.5539/ass.v7n12p201

URL: http://dx.doi.org/10.5539/ass.v7n12p201

\begin{abstract}
As a new type of organization, non-profit organizations have proposed new requirements on leadership practice and development of theory. There are three inadaptations existing in the traditional organization and leadership pattern to the internal leadership of non-profit organization, namely, inadaptation to changes of relationship between leaders and followers, inadaptation to uncertainty of decision-making foundation and inadaptation to innovative development of the organizations. This article discusses on the leadership strategies of Chinese non-profit organizations in four aspects: integration of certainty of the target and mission with ideology, resource integration with the target of ensuring funding channels, integration of all personnel in performance evaluation standard and member stimulation exploration and organizational integration in the double organizational structure.
\end{abstract}

Keywords: Non-profit organizations, Organization and leadership, Leadership strategies, Integration

Study on Chinese non-profit organizations has just started with growth of Chinese non-profit organizations in the past two decades or so. Study on internal leadership strategies in Chinese non-profit organizations is a brand-new subject in the scientific field of Chinese leadership. However, swift development of Chinese non-profit organizations and their responsibilities in the social life as well as the confusions of this sort of organizations in their own developmental practice further indicate the profound significance of this study.

\section{The attribute of Chinese non-profit organizations and definition to the research subject}

Considering the current academic common sense and the actual national situation of China, the author believes that the attribute of Chinese non-profit organizations should include two aspects of content. On one hand, in terms of organizational operation, non-profit organizations ought to have organizational, self-governance, non-governmental, non-profit and public benefit features. The most fundamental attribute is the non-profit and its profit should be added and invested in activities and should not be for private distribution. On the other hand, in terms of organizational culture, non-profit organizations ought to have a definite mission. Whether in public benefit organizations or mutual benefit organizations, mission is the premise for non-profit organizations to survive and is also the internal support of their non-profit feature and basic source power for development of non-profit organizations.

Chinese non-profit organizations mentioned here in this paper has the similar connotation with non-governmental organizations (social organizations) generally termed by current Chinese government sections and are mainly concerned with such social organizations as social associations and foundations. Here, considering the speciality of non-governmental non-enterprise units, such as, hospitals and schools, are not deemed as the research subject.

2. Inadaptation of the traditional organization and leadership style to internal leadership within the non-profit organizations

Since internal leadership in Chinese NPOs are different from the traditional government and corporate organization leadership (hereinafter referred to as traditional organization and leadership), there are at least three 
inadaptations in the traditional organization leadership style to the internal leadership of Chinese NPOs.

2.1 Inadaptation of the traditional organization and leadership style to changes of relationship between leaders and followers

With gradual self-governance of Chinese NPOs, great changes have taken place in relationship between leaders and followers in NPOs compared with the relationship in profit making organizations and governmental organizations. In profit making organizations or governmental organizations, leaders possess the manipulation on organization resources and can thus often mobilize enthusiasm of followers so as to take up an active position in the leadership activities. In contrast, in NPOs, followers are usually providers of the financial resources and material resources of the organizations, so it is these followers who actually possess manipulation on resources of the organizations. As a consequence, great changes have taken place in relationship between leaders and followers due to the provision of organizational resources. In traditional leadership activities, it is habitual that followers are regarded as those who are led. It seems that in the interactive relationship between leaders and followers, it is often the latter that are always at a passive position, whereas leaders are always at an active and predominant position. Concern of leaders for their followers is analyzed as the personnel-oriented leadership behavior and their concern for the work is termed as task-oriented leadership behavior, which is the basic dimension for the traditional leadership theory to analyze the leadership behaviors. Just as a work instrument, followers should under manipulation of their leaders. On the contrary, in NPOs, leaders neither possess the manipulation on followers as is often the case in other sorts of organizations as a result of the economic contractual relationship nor possess the privilege to distribute and occupy scarce resources in organizations. In NPOs, to a great extent, the reward and punishment and incentive mechanism of leaders in traditional organizations may go out of order. A series of problems that are caused as a result of changes in relationship between leaders and followers is the greatest inadaptation of the traditional organization leadership style to internal leadership of NPOs.

\subsection{Inadaptation of the traditional organization and leadership style to uncertainty of decision making} foundation

Since NPOs depend much on provision of resources by the government, profit making organizations or donators and volunteers, together with the fact that a large majority of products provided by NPOs are service behaviors, but not material products, great uncertainty exists in foundation of decision making by NPOs.

Decision making of leaders in NPOs often has to give priority to preference of individuals of donators or volunteers or the government (Note 1) or enterprises in the name of a donator or volunteer. How to maintain balance among a variety of preferences of the multitude of resource providers and not to deviate from the tenet of the mission of the organizations is, indeed, a sort of challenge for leaders in Chinese NPOs.

Evaluation on quality of the intangible service products provided by NPOs is really of a difficult issue. Furthermore, this kind of products mostly benefits a third party. That is, the donators and voluntary service providers themselves do not benefit from the products directly and there is a great gap between the intention of the party who purchases the products and recognition of the party who benefits. Therefore, there exists a great challenge to the evaluation mechanism and incentive mechanism in the traditional leadership activities. The great uncertainty in decision making foundation makes the decision making means and methods in the traditional organization leaders difficult to go forward, which necessarily calls for a more appropriate style and method to finish operation of the organization.

\subsection{Inadaptation of the traditional organization and leadership style to innovative development of organizations}

The most fundamental purpose of a leadership activity is to satisfy adaptation of the organizations, which must guarantee innovation of the organizations. Especially, in the process of independent self-governance of current Chinese NPOs, leaders should more satisfy vitality of the organizations and adapt to the organizations. Otherwise, it would be difficult for the organizations to continue to develop and the organizations may also be rapidly eliminated. Therefore, for the Chinese NPOs in the process of development, organizational innovation is just as the life of the organization. This requires leaders of the organization to mobilize all positive elements in the organization and guarantee innovation of the organization. The inherent defects in traditional leadership activities can't totally adapt to this organizational innovation. In traditional leadership activities, on one hand, it restrains and controls people with strict rules and regulations and manipulates people with skills having ulterior motives to make people docile and obedient and dedicated to work. On the other hand, it extravagantly hopes that employees can have inexhaustible energy, get rid of the stale and bring for the fresh and make contributions without protest and wholeheartedly so as to make the organization to be able to continuously go towards brilliance in innovation and positive response. It is ignored that blind meticulousness and obedience of followers 
and flexible thinking and active innovation are two totally different working and thinking conditions. This kind of contradiction between rule and flexibility and constraint and freedom reflects inadaptation of the traditional organization leadership style to innovative development of the organizations.

There are several inadaptations of the traditional organization leadership style to NPOs which are not only confined to the above three aspects. As a new type of organization, NPOs have proposed new requirements on development of leadership practice and theory. Therefore, we have to explore leadership strategies in Chinese NPOs in re-introspection on leadership activities and leadership theories.

\section{Discussion on internal leadership strategies in Chinese non-profit organizations}

Given inadaptations of traditional organization leadership style to internal leadership of NPOs, the following section is going to discuss the organization and leadership strategies in Chinese NPOs from four aspects, namely, integration of certainty of the target and mission with ideology, resource integration with the target of ensuring funding channels, integration of all personnel in performance evaluation standard and member stimulation exploration and organizational integration in the double organizational structure.

\subsection{Integration of certainty of the target and mission with ideology}

Mission of NPOs is given priority and whether the contributors or volunteers come together from all over the world for a common mission. Thus, confirmation of the target mission of NPOs is the core issue in the organizations.

So far as the current situation is concerned, Chinese NPOs are able to provide a variety of services, mainly including six categories, namely, health care, education and research, social service, arts culture, association, trade association and chamber of commerce. As a result of different reasons, these organizations may sometimes tend to have multiple targets or missions, whereas these targets and missions are sometimes even mutually contradictory, which gives rise to dispersed energy among leaders and heavy tasks on the shoulder of leaders. Furthermore, due to the basic feature of "non-profit making" of NPOs, the development of the organizations are unlikely to be measured by the specific and single performance standard of profit. Therefore, it is a significant subject of the leaders in NPOs to set up the target and mission of the organizations in an accurate and objective way. NPOs do not only provide a variety of services, but also offer a channel to express the feelings for expression of all kinds of beliefs and ideology. The target and mission of the organizations fundamentally originate from the ideology of organization members. Ideology is usually the primary reason for establishment of many NPOs. Those who have set up these NPOs generally have a strong belief and are willing to spend time and money to realize their idea. These beliefs not only include religious, worldly and political beliefs, but also include different artistic concepts and also recognition of such particular theories about education, science and children development, etc. How to integrate the ideology with multiple backgrounds into the target and mission of the organizations that are healthy and accepted by organization members and have public benefit is a primary task of leaders in NPOs and is also the fundamental precondition for the organizations to form a joint force.

\subsection{Resource integration with the target of ensuring funding channels}

Mostly, funding channels of NPOs come from three sources, namely, social donation, service charge and government grant.

So far as the current situation in China, for social donation, leaders of NPOs have to come to clear awareness that in the market economy situation in which the actual condition is that the social resources are limited and service costs rise highly, NPOs must have a reasonable reason to compete with multiple institutions for limited resources. Therefore, leaders of NPOs have to enhance the public trust of the organizations to collect funds for operation through effective running of the organizations, which is a hard task for leaders in NPOs.

Since NPOs are different from governmental organizations, for service charge, they can only employ the pattern of voluntary charging. If the charge is too high, it will necessarily violate the precondition of public benefit of NPOs and breed the disgusting emotion among the public.

As for government grant, Salamon proposed a theory of "entrusting government". The government entrusts the task of providing public service to NPOs to assume in order to realize its own target, whereas the government is responsible for the funds support and the NPOs take the responsibility of providing service. At present, a large majority of NPOs in China choose the path of independent self-governance through restructuring, and the direction of restructuring is to "unhook" and "break away". Thus, concern and support of the government seems trivial under the great circumstance of reform. Nevertheless, leaders in Chinese NPOs should still keep in touch with the government since they expect to gain trust and support of the government and maintain the perfect operation of the organizations in making the best of both the worlds. 
As for the three kinds of funding channels, leaders of NPOs should strengthen integration of the three categories of resources on the precondition of conducting a profound study on the features of each different channel to make the three fund flows become the fundamental security for development of NPOs.

\subsection{Integration of all personnel in performance evaluation standard and member stimulation exploration}

Development of NPOs totally depends on the enriched interpersonal relationship and agglomerated popularity, but leadership of NPOs is faced up with the two awkward predicaments of uncertainty of performance evaluation standards and difficulty of member incentive mechanism in operation. At the same time, since the identity of members in Chinese NPOs has the characteristics of diversification, it can be generally classified into three categories, namely, volunteers, employees employed under contract and paid staff (Note 2). The sponsors or donators can be both volunteers and can be paid staff, or do not participate in operation of a project just with the identity of a sponsor. Thus, internal leadership of Chinese NPOs should realize integration of performance evaluation standard and all personnel in exploration of member incentive.

Most products that NPOs provide are intangible public service products, so the service technique and service effects are difficult to be quantified. Performance evaluation standard of organization members is difficult to be confirmed. Therefore, the performance evaluation of the organizations ought to depend on timely feedback of the service objects and long-term supervision of social efficacy. As for incentives among members, we should also make explorations among different types of members on the precondition of gradually confirming the evaluation standard.

Since volunteers are voluntary and have no direct economic contractual relationship with the organizations, and some are even major donators, so leadership and control on these volunteers is relatively difficult. In the meantime, the professional quality training among volunteers and management of potential risks in voluntary service, etc., all propose new challenges to internal leadership of NPOs.

We have to take into consideration of the stability of the team in incentives among paid employees in NPOs. Instability of the team of volunteers requires the stability of the team of paid employees to ensure the mission of the organizations and the stable development of the organizations. Leaders of NPOs have to come to realize clearly that the promotion channel in the structure of NPOs is narrow and the compensation and treatment is limited, and it is a austere and realistic problem the leaders of NPOs have to face how to retain talents with constraints of a varieties of realities and reduce turnover costs of labor force.

As for sponsors or donators, whether they serve as the volunteers or paid employees, leaders of NPOs have to make them have sufficient confidence in face of the organizations and let them come to a clear understanding of the social benefit, developmental strategies and developmental situation of the organizations and even the predicament the organizations are encountered. From another perspective, this category of people can be deemed as the service subjects of NPOs and the service content is to employ their money and wealth to a satisfactory project and gain a better social benefit that is consistent with the original intention. Therefore, we have to guarantee smooth communication between the sponsors and the organizations and security of trust and communication is also the foundation for the funding channels.

Let's come to summarize functions of the three sorts of personnel in the NPOs. Volunteers are the vitality, employees are stability and sponsors are security. Therefore, leaders of NPOs have to realize benign interaction of the three kinds of personnel on the precondition to ensure that individualism demands of the three sorts of personnel. According to the author, first of all, we should guarantee enthusiasm of paid staff on the precondition of formulating an incentive mechanism among members of the organizations since regular employees should also have interaction in work with volunteers, sponsors and service subjects of a project. To a certain extent, regular staff stand for the organizations. Therefore, incentive of the organizations on volunteers and sponsors can both be conveyed through regular staff. In realizing incentive on regular staff, the organizations have to regard volunteers and sponsors as another category of service subject of the organizations since the service they require mostly is spiritual.

\subsection{Organizational integration in the double organizational structure}

In the organizational structure of NPOs, neither the formal hierarchical structure of the governmental organization nor the explicit power division in enterprises can be found. One unique feature of the multiple NPOs is that these organizations are constituted by two different systems, one system responsible for development of resources and the other system responsible for offering service. However, there is only one system in enterprises to take responsibility of both of these functions. The primary reason for formation of the double systems is that NPOs depend on specialization to enhance efficiency. Obviously, NPOs with this sort of 
structure possess two categories of external customers. The first category is capital providers, such as, individuals, enterprises or government. And the other category is those who receive the service. All these characteristics make internal leaders of NPOs more elaborate in their leading work.

In operation of the double organizational structure, leaders of NPOs have to take into consideration of the differences in functions of the two sorts of organizations and provide distinguished timetable and distinguished remuneration as well as spiritual incentive. Similarly, they should also integrate members of these two categories of organizations with different functions within a common organizational mission framework. There should be no reason for violating the organizational mission of public benefit of NPOs. Leaders of NPOs have to grasp the relevance of the double systems of the organizations and let them supplement each other instead of going against each other.

\section{References}

Peter F. Drucker. (1994). Theory of Management for Non-Profit Institutions, translated by Yu, Peishan. Taipei: Yuan-Liou Publishing Co., Ltd., 3-7.

Salamon L. M \& Anheier H.K. (1997). Defining the Non-profit Sector. London: St.Martin.

Wu, Dongmin \& Dong, Ximing. (2003). Non-profit Organization Management. China Renmin University Press, p.6.

Xie, Sixin, Zhang, Jincheng \& Zong, Jiafeng. (2002). The Management Theory of the Western Non-Profit Organizations and its Significance for Reference. Nankai Journal (Philosophy, Literature and Social Science Edition), No. 2.

\section{Notes}

Note 1. The government establishes the system in which the government purchases service by the trade associations and for the business activities conducted by the trade associations entrusted by the government or the service provided by the trade associations, the government should defray corresponding expenses and the capital required should be brought into budget management. NO. 36 (2007) of the General Office of the State Council in "Some Opinions of the General Office of the State Council about Accelerating and Promoting the Reform and Development of Trade Associations and Chambers of Commerce".

Note 2. At present, the civil staffing of government affiliated institutions with similar treatment to civil servants is still maintained among regular employees in some domestic organizations, such as, consumers' association in local areas. 